\title{
Potential Toxicity in Crucian Carp Following Exposure to Metallic Nanoparticles of Copper, Chromium, and their Mixtures: A Comparative Study
}

\author{
Yuxuan Liu, Zhenhua Yan*, Jun Xia, Kun Wang, \\ Xin Ling, Bingcheng Yan \\ Key Laboratory of Integrated Regulation and Resources Development of Shallow Lakes of the Ministry of Education, \\ College of the Environment, Hohai University, Nanjing 210098, China
}

Received: 22 January 2017

Accepted: 1 March 2017

\begin{abstract}
Although study of the toxicity of metallic nanoparticles in aquatic organisms is increasing, there is still little known about their combined toxicity, especially in a comparative and integrated approach. The objective of this study is to compare the toxicity of copper nanoparticles (CuNP), chromium nanoparticles (CrNP), and their mixtures to crucian carp (Carassius auratus) through a comprehensive approach. A high median lethal concentration of CuNP $(390.75 \mathrm{mg} / \mathrm{L})$ and $\mathrm{CrNP}(551.03 \mathrm{mg} / \mathrm{L})$ was calculated from the acute toxicity, indicative of low toxicity to crucian carp. After exposure for $10 \mathrm{~d}$ at sublethal concentrations, several biomarker responses, including the activities of brain acetylcholinesterase (AChE), gill sodium/ potassium-activated ATP $\left(\mathrm{Na}^{+} / \mathrm{K}^{+}\right.$-ATP), liver superoxide dismutase (SOD), and catalase (CAT) were significantly inhibited by all nanoparticles in most cases, implying the neurotoxicity, osmoregulatory toxicity, and oxidative damage of metallic nanoparticles. Thereafter, the integrated biomarker response version 2 (IBRv2) integrating all biomarker responses was applied to compare the toxicity, and therefore the toxicity order was tentatively proposed as: the mixtures $\approx \mathrm{CuNP} \square \mathrm{CrNP}$, suggesting a synergistic effect in the mixtures. The findings will help to understand the ecological impacts of metallic nanoparticles in an aquatic environment in a more complete and accurate picture.
\end{abstract}

Keywords: metallic nanoparticle, combined toxicity, biomarker response, IBRv2, Carassius auratus 


\section{Introduction}

Due to their unique physical and chemical properties, metallic nanoparticles have applicability in advanced mechanical materials, electronics, conductive coatings, medicine, cosmetics, catalyzers, and sensors, and are regarded as the second class of manufactured nanomaterials [1]. It is therefore likely that metallic nanoparticles are inevitably disposed and released into the aquatic environment during the processes of fabrication, use, waste disposal, and recycling, with the predicted concentrations at $\mu \mathrm{g} / \mathrm{L}$ in the environment [2]. As a result, humans and organisms are likely exposed to these nanoparticles, and concerns about their environmental and ecological consequences are rapidly increasing.

Previous studies have found that nanoparticles may be able to pass through cell walls and membranes, and then cause growth inhibition, inflammation, oxidative stress, and metabolic disturbance in non-target organisms [3-5]. However, most studies have been conducted primarily based on testing a single metallic nanoparticle to understand its potential threat to organisms. Under environmental conditions, in fact, metallic nanoparticles are frequently released as a mixture due to their complex usage in different products, leading to a distinctly different toxicity profile in organisms from those of individuals. For instance, the antibacterial property of silver nanoparticles toward Escherichia coli was markedly suppressed by the presence of hematite nanoparticles due to aggregation [6], while the toxicity of copper nanoparticles (CuNP) to human cells was enhanced by the nano- $\mathrm{ZnO}$ at nontoxic concentrations [7]. Tong et al. [8] have proposed that the interaction and surface complexation reaction between different nanoparticles could significantly alter the original toxicity of individual nanoparticles, and more concerns should be taken into the combined toxicity of different nanoparticles in the environment.

Among the metallic nanoparticles, CuNP have been used as industrial additives for lubricants, plastics, and metallic coatings, inks, and also as an antimicrobial alternative in human health and agriculture [9]. Chromium nanoparticles (CrNP) are mainly applied in catalysts, pigments, and electroplating and tanning processes, as well as trace elements in food additives [10-11]. Due to their continuous release into the aquatic environment, both acute and chronic toxicity of CuNP have been observed in various aquatic species, including phytoplankton, zooplankton, and fish, in which CuNP showed similar types of toxic effects as ionic $\mathrm{Cu}$ [12-16]. In our previous study, the presence of CrNP significantly inhibited the reproduction and growth of Daphnia magna, and the antioxidant enzyme activities were simultaneously decreased [17]. However, to the best of our knowledge, the potential toxicity of CrNP to fish has not been reported in the literature, not to mention their combined toxicity.

To characterize the toxic effects of environmental pollutants on aquatic organisms, a series of biomarker responses - including different biological functions in aquatic organisms - have been strongly recommended, with more sensitive and biologically relevant information on the potential impact of pollutants on the health of organisms [18]. All of these biomarkers are thereafter integrated into a general scheme, termed as the "integrated biomarker response" (IBR) index, to provide a simplified and comprehensive interpretation of the health status of the aquatic organism [19-20]. Although the biomarker responses of different metallic nanoparticles on aquatic organisms have been studied, the application of the IBR index in nano-toxicological studies has received little attention.

Thereafter, the goal of the present study was to compare the toxicity of CuNP, CrNP, and their mixtures in crucian carp (Carassius auratus), which can be found in fresh water throughout China and has been widely used in various toxicity tests [21]. Following waterborne exposure to different concentrations of CuNP, CrNP, and their mixtures, multiple biomarker responses in fish, including activities of acetylcholinesterase $(\mathrm{AChE})$ in the brain, sodium-potassium-activated ATP $\left(\mathrm{Na}^{+} / \mathrm{K}^{+}\right.$ATP) in the gill, and superoxide dismutase (SOD) and catalase (CAT) in the liver, were determined to assess the neurotoxical, osmoregulatory, and antioxidant effects. Biomarker responses were then simplified and quantized using the IBR index (version 2) to compare the potential toxicity of CuNP, CrNP, and their mixtures in fish. The results will provide a more complete and accurate picture of the ecological impacts of metallic nanoparticles in an aquatic environment.

\section{Materials and Methods}

\section{Chemicals Used}

Commercial bare CuNP (purity: $>99 \%$, particle size: $54 \mathrm{~nm}$, specific surface area: $24 \mathrm{~m}^{2} / \mathrm{g}$ ) and CrNP (purity: $>99 \%$, particle size: $88 \mathrm{~nm}$, specific surface area: $12 \mathrm{~m}^{2} / \mathrm{g}$ ) used in the present study were obtained from Nachen S\&T (Beijing, China) as a powder. Kits for the determination of biomarker responses in fish were provided by Jiancheng Bioengineering Institute (Nanjing, China). Tricaine methane sulfonate (MS-222) was purchased from J\&K Scientific (Shanghai, China). Ultrapure water was purified with a Milli-Q water purification system (Millipore, Milford, MA, USA). All other chemicals used were of analytical grade and obtained from Sinopharm Chemical Reagent Co., Ltd. (Shanghai, China).

\section{Nanoparticle Preparation and Characterization}

The stock suspension of each nanoparticle was prepared by dispersing in ultrapure water with an ultrasonoscope having an output of $250 \mathrm{~W}$ at $40 \mathrm{kHz}$ for $60 \mathrm{~min}$ at $23^{\circ} \mathrm{C}$ every day. The exposure solutions were further prepared by diluting the stock suspension with test water to a series of concentrations and then sonicating for $30 \mathrm{~min}$ prior to exposure. The morphology and size of each nanoparticle in exposure solutions (all at $80 \mathrm{mg} / \mathrm{L}$ ) were characterized 
by a transmission electron microscopy (TEM, JEM-2100, JEOL, Japan) and a Malvern Mastersizer 2000 (Malvern, $\mathrm{UK})$.

\section{Fish Maintenance}

Juvenile crucian carp of both sexes (weight: $25.23 \pm 4.12 \mathrm{~g}$, length: $9.7 \pm 0.85 \mathrm{~cm}$ ) were purchased from the Nanjing Institute of Fishery Science (Nanjing, China). They were initially acclimatized for at least two weeks prior to exposure in an aquarium containing $150 \mathrm{~L}$ dechlorinated municipal water. During the acclimatization, fish were fed with commercial fish pellet food with $6 \%$ of body weight every day. Residues in the aquarium were removed every day. Fish were not fed for $24 \mathrm{~h}$ before exposure and no food was provided during the exposure period.

During acclimatization, the water quality was controlled at a steady state: temperature, $23 \pm 2^{\circ} \mathrm{C}$; $\mathrm{pH}, 7.5 \pm 0.5$; dissolved oxygen $>90 \%$; total hardness, $105 \mathrm{mg} / \mathrm{L} \mathrm{CaCO}_{3}$; natural illumination. Animal care and exposure protocols followed the national and institutional guidelines for animal welfare.

\section{Exposure Designs}

To study the acute toxicity of metallic nanoparticles, fish (10 per tank) were randomly assigned to a series concentrations of CuNP $(0.05,0.1,0.2,0.4$, and 0.8 $\mathrm{g} / \mathrm{L}), \operatorname{CrNP}(0.075,0.15,0.3,0.6$, and $1.2 \mathrm{~g} / \mathrm{L})$, and a blank control (water only) for 96 consecutive $\mathrm{h}$. In each exposure treatment, three replicate tanks were conducted independently, and no food was supplied during the exposure. The exposure solution in each tank was renewed daily to maintain stable concentrations. The water conditions were kept the same as for acclimatization. Exposures were monitored every $12 \mathrm{~h}$ for death, which was defined as lack of response to physical prodding. Cumulative mortality of fish within $96 \mathrm{~h}$ after exposure was used for the calculation of median lethal concentration $\left(\mathrm{LC}_{50}\right)$.

Based on the results of the acute toxicity study, the sublethal toxicity of metallic nanoparticles to fish was further evaluated. Fifteen fish were randomly exposed to the following different treatments for $10 \mathrm{~d}$ : CuNP alone and CrNP alone at concentrations of 10, 20, 40, and $80 \mathrm{mg} / \mathrm{L}$. Their combined exposures were prepared according to an equiconcentration ratio of $1: 1$ and the total exposure concentrations were also 10, 20, 40, and $80 \mathrm{mg} / \mathrm{L}$. A blank control was also conducted. All treatments were conducted in semi-static, with half of the experimental solutions replaced every day. There were three replicate tanks per treatment, and no food was supplied during the exposure periods. The water quality parameters were maintained as well as acclimatization during the exposure periods.

Following exposure for 2, 6, and $10 \mathrm{~d}$, four fish were sampled from each tank (12 fish in total in each treatment) and anaesthetized with MS-222 (300 mg/L). After killing the fish by cutting their spine as close to the cranium as possible, the brain, gill, and liver tissues were immediately collected, washed quickly with $0.15 \mathrm{M}$ of ice-cold $\mathrm{KCl}$, and flash frozen in liquid nitrogen.

\section{Biomarker Response Analysis}

Brain samples were homogenized in ice-cold phosphate buffer (1:9 w/v, 0.1 M, pH 7.2) containing Triton-X 100, and then the centrifuged supernatants were collected for AChE activity determination. After being homogenized in ice-cold Tris- $\mathrm{HCl}$ buffer $(10 \% \mathrm{w} / \mathrm{v}, 0.1 \mathrm{M}, \mathrm{pH} 7.4)$, liver samples were centrifuged and the supernatants were collected for antioxidant enzyme determination. Gill samples were homogenized in 40 volumes of ice-cold imidazole buffer $(0.04 \mathrm{M}, \mathrm{pH} 7.0)$ and then centrifuged for further $\mathrm{Na}^{+} / \mathrm{K}^{+}$-ATP activity assay.

All biomarker responses were measured with commercial kits obtained from Jiancheng Bioengineering Institute (Nanjing, China), according to the manufacturer's instruction. The activity of AChE in brain was determined at $412 \mathrm{~nm}$ using a microplate reader (BioTek, USA), and the results were expressed as U/mg protein. One unit of $\mathrm{AChE}$ was defined as the amount of enzymes that catalyzes the hydrolysis of $1 \mu \mathrm{mol}$ of acetylthiocholine iodide per minute. Liver SOD activity was determined at $550 \mathrm{~nm}$ and expressed as U/mg protein. One unit of SOD was defined as the amount of enzyme to cause 50\% inhibition of the reduction of nitroblue tetrazolium. CAT activity was monitored at $240 \mathrm{~nm}$ and the results were expressed as $\mathrm{U} / \mathrm{mg}$ protein. One unit of CAT was defined as the amount of enzymes that catalyzes the decomposition of $1 \mu \mathrm{mol}$ of hydrogen peroxide per minute. The $\mathrm{Na}^{+} / \mathrm{K}^{+}$-ATP activity in the gill was read at $660 \mathrm{~nm}$ in the microplate reader, and determined as the difference between total inorganic phosphate released without ouabain and inorganic phosphate released using $3 \mathrm{mM}$ ouabain. The activity of $\mathrm{Na}^{+} / \mathrm{K}^{+}$-ATP was then expressed as $\mu \mathrm{mol} \mathrm{Pi}$ liberated $/ \mathrm{mg}$ protein/h.

The protein content of each sample was measured to normalize all biomarker responses using a protein assay kit (Coomassie brilliant blue G-250, Jiancheng Bioengineering Institute, Nanjing, China) with absorbance at $595 \mathrm{~nm}$.

\section{IBR Calculated}

To address all biomarker responses as a whole, an integrative tool named IBR was applied to evaluate the integrated toxicity of different metallic nanoparticles in fish. The original IBR tool was developed by Beliaeff and Burgeot [19], and subsequently updated by Sanchez et al. [20] to version 2 (IBRv2).

For the IBRv2 calculation, individual biomarker responses $\left(\mathrm{X}_{\mathrm{i}}\right)$ were first compared to the mean value of biomarker responses from the control $\left(\mathrm{X}_{0}\right)$, and then log transformation was used to reduce variance:

$$
Y_{i}=\log \frac{X_{i}}{X_{0}}
$$


Secondly, the $\mathrm{Y}_{\mathrm{i}}$ was standardized according to equation (2):

$$
Z_{i}=\frac{Y_{i}-i}{\dot{o}}
$$

... where $Z_{\mathrm{i}}$ was the standardised value of each biomarker response, and $\mu$ and $\sigma$ were the general mean value and the standard deviation of $\mathrm{Y}_{\mathrm{i}}$ for each biomarker response in all treatments, respectively.

Thirdly, a deviation index $\left(\mathrm{A}_{\mathrm{i}}\right)$ was calculated from the standardized value of each biomarker response $\left(Z_{i}\right)$ and the standardized value of the control $\left(\mathrm{Z}_{0}\right)$.

$$
\mathrm{A}_{\mathrm{i}}=Z_{i}-\mathrm{Z}_{0}
$$

The values of $A_{i}$ were then shown in a star plot for a visual inspection of all biomarker responses, in which case the value of $\mathrm{A}_{i}$ up to 0 reflected biomarker response induction, and the values of $A_{i}$ down to 0 indicated a biomarker response inhibition.

Finally, to obtain an integrated multi-biomarker response named IBRv2, the absolute value of $\mathrm{A}_{\mathrm{i}}$ for each biomarker in the same treatment were summed as follows:

$$
\operatorname{IBRv} 2=\sum_{\mathrm{i}=1}^{n}\left|A_{i}\right|
$$

\section{Statistical Analysis}

All statistical analyses were performed using SPSS Statistics 17.0. All data from different treatments and control were expressed as mean \pm standard deviation (SD), and first tested for normality and homogeneity variance using Shapiro-Wilk's and Levene's tests, respectively. A one-way analysis of variance (ANOVA) followed by Dunett's test was used to analyze the statistical differences between the control and each treatment. All differences were considered significant at $P<0.05$.

\section{Results and Discussion}

In the exposure solutions, all particles showed some degree of aggregation, but the diameter of most nanoparticles is still less than $100 \mathrm{~nm}$. The dissolved form of target metal in waters were also measured, and the dissolution rates ranged from $4 \%$ to $10 \%$.

\section{Acute Toxicity}

No mortality was observed in the control during the exposure periods. As shown in Fig. 1, CuNP and CrNP were all toxic to crucian carp, with the calculated $96 \mathrm{~h}$ $\mathrm{LC}_{50}$ value of $390.75 \mathrm{mg} / \mathrm{L}$ for CuNP and $551.03 \mathrm{mg} / \mathrm{L}$ for CrNP. These results are consistent with previous studies, in which nanoparticles can be lethal to fish in the
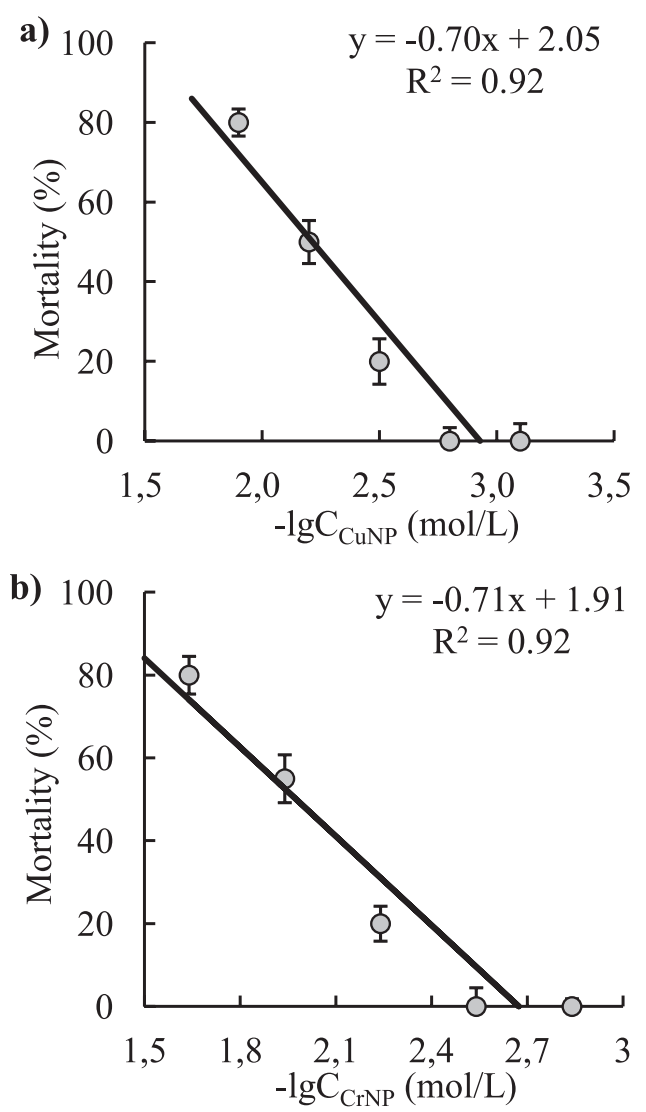

Fig. 1. Concentration-response plots of a) $\mathrm{CuNP}$ and b) $\mathrm{CrNP}$ acting on crucian carp.

$\mathrm{mg}-\mu \mathrm{g} / \mathrm{L}$ range, depending on the type of material [22]. According to the guidelines of HJ/T 154-2004 of China [23], if the $96 \mathrm{~h} \mathrm{LC}_{50}$ value of a compound is more than $100 \mathrm{mg} / \mathrm{L}$, the compound is considered to be less toxic to fish. Hence, both CuNP and CrNP were regarded as less toxic to crucian carp, and CuNP was more toxic than CrNP under the same conditions. However, Griffitt et al. [24] reported a quite low acute toxicity of CuNP to zebrafish (Danio rerio), with the $48 \mathrm{~h} \mathrm{LC}_{50}$ value of $1.5 \mathrm{mg} / \mathrm{L}$. The $48 \mathrm{~h} \mathrm{LC}_{50}$ values of CuNP and CrNP to Daphnia magna were also much lower than the present study [17]. The different acute toxicity results are possibly attributed to the different species used as test organisms - especially with different body sizes and weights, considering crucian carp always are larger. The acutely toxicological mechanism of metallic nanoparticles to aquatic organisms is still unclear. As reviewed by Shaw and Handy [22], one concept in metallic nanoparticles toxicity is that the acute toxicity to fish may be driven by the released free metal ions from the nanoparticles. This suggests that the observed mortality of fish in this study may be partly attributed to the released free metal ions, since $\mathrm{Cu}$ and $\mathrm{Cr}$ ions were more acutely toxic to crucian carp than the nanoparticle forms [25]. In addition to the released ions, metallic nanoparticles may also have an intrinsic property that confers toxicity, which has nothing to do with their morphological properties such as size, surface area, or zeta potential in the same waters [26]. 

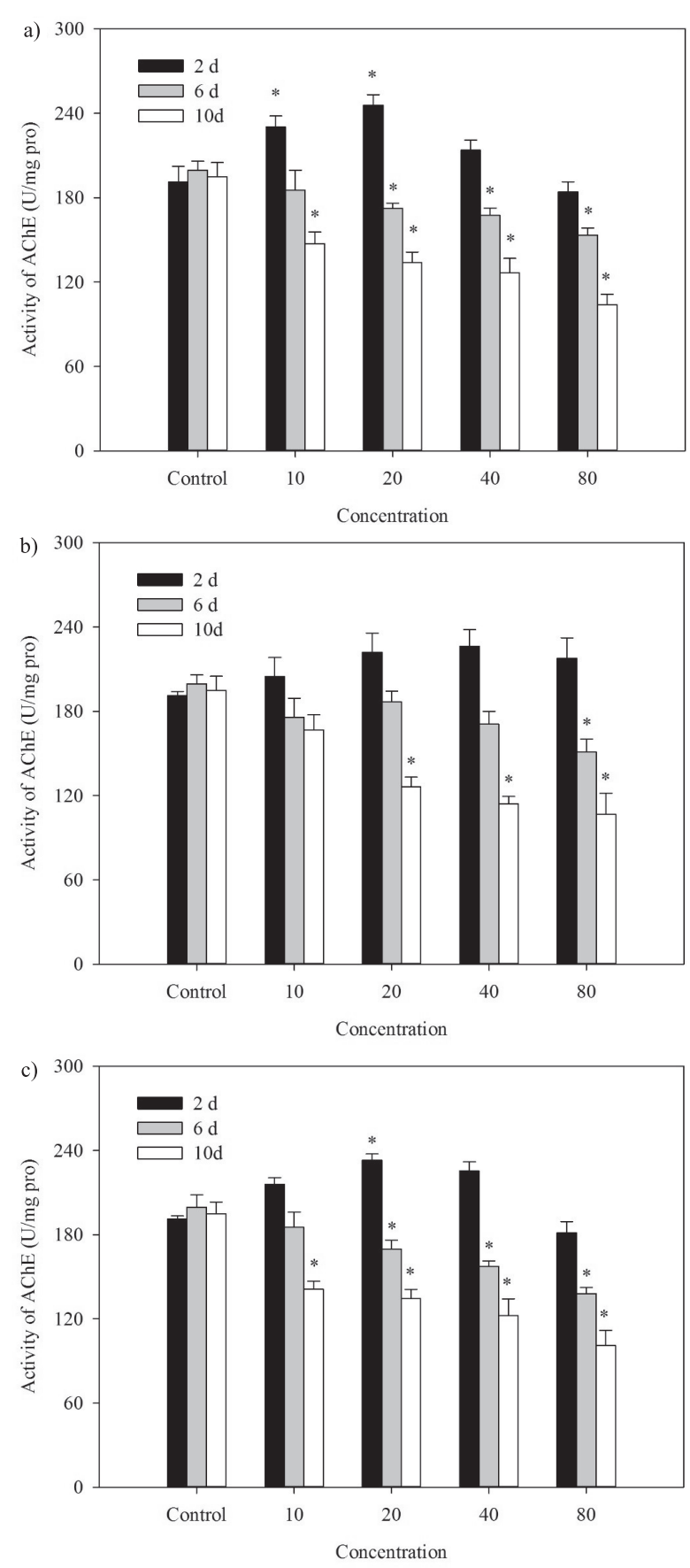

Fig. 2. The changes of brain AChE activity in fish after exposure to a) $\mathrm{CuNP}$, b) $\mathrm{CrNP}$, c) and the mixtures. Asterisks indicate values that are significantly different from the control $(P<0.05)$.

\section{Biomarker Response}

To assess the sublethal toxicity of metallic nanoparticles, a series of biomarker responses related to neurotransmitter conduction, osmoregulation, and antioxidant capacity in fish were further evaluated. During the exposure periods, no mortality or abnormal behavior of fish was observed in any treatments.

The enzyme of AChE plays a vital role in hydrolysis of the neurotransmitter acetylcholine to ensure the intermittence of nerve impulses responsible for neuronal communication [27]. Changes of AChE enzymatic activity may alter many physiological functions in aquatic organisms, such as locomotion, predator evasion, prey location, and orientation [28]. In the present study, CuNP and the mixtures at low concentrations significantly elevated the activity of brain AChE enzyme after $2 \mathrm{~d}$ exposure (Fig. 2), which may facilitate the elimination of acetylcholine in cholinergic synapses and protect organisms from toxic harm in a compensatory manner [29]. Interestingly, at high concentration, metallic nanoparticles resulted in a significant decrease in the activity of AChE enzyme after exposure for $6 \mathrm{~d}$. These decreases were further reduced by CuNP (24-47\%), CrNP (14-45\%), and the mixtures (28-48\%). This suggests that $\mathrm{CuNP}$ and CrNP (alone or in combination) could significantly reduce the synthesis of $\mathrm{AChE}$ in the neurons and have neurotoxic effects. The inhibition of AChE activity could result in the accumulation of acetylcholine in the synaptic cleft and then lower the nerve information exchange via voltagegated sodium channels [30]. As suggested by Fonte et al. [31], the relatively low-moderate inhibition of AChE activity in the aquatic organisms decreased the movement coordination and predatory behavior, and further threaten individual survival and population development.

The responses of $\mathrm{Na}^{+} / \mathrm{K}^{+}$-ATP enzymatic activity in the gill are presented in Fig. 3. Compared to the controls, CuNP alone or in combination with $\mathrm{CrNP}$ at high concentrations significantly induced enzyme activity after $2 \mathrm{~d}$ exposure. No significant alteration of the $\mathrm{Na}^{+} / \mathrm{K}^{+}$-ATP enzymatic activity was observed in fish exposed to any treatments for $6 \mathrm{~d}$. On the contrary, after exposure for $10 \mathrm{~d}$, an obvious decrease in the activity of $\mathrm{Na}^{+} / \mathrm{K}^{+}$-ATP enzyme occurred in fish treated with CuNP (23-52\%) or the mixtures $(26-52 \%)$ in most cases, as well as a $21-27 \%$ decrease in the CrNP treatments at high concentrations $(\geq 40 \mathrm{mg} / \mathrm{L}$ ). It is well known that the $\mathrm{Na}^{+} / \mathrm{K}^{+}$-ATP enzyme is responsible for transporting $\mathrm{Na}$ and $\mathrm{K}$ ions through the cell membranes and thus maintains the balance in osmotic pressure and membrane permeability [32]. Significant alterations of gill $\mathrm{Na}^{+} / \mathrm{K}^{+}$-ATP enzyme could disrupt the gill secretory processes and may impact respiration, osmoregulation, acid-base balance, nitrogen excretion, and metabolism of circulating hormones in this tissue [33]. The results of the present study suggest that CuNP and CrNP may have some additional osmotic stress in the gill, causing adverse effects in fish. Similar results were also found in juvenile Epinephelus coioides, in which the activity of the $\mathrm{Na}^{+} / \mathrm{K}^{+}$-ATP enzyme was significantly decreased by $\mathrm{CuNP}$, indicating an osmoregulatory impairment in mitochondria and an increase in membrane permeability [34]. After investigating the relationship between branchial $\mathrm{Na}^{+} / \mathrm{K}^{+}$-ATP activity and $\mathrm{Cu}$ ion concentrations in plasma and carcass, Shaw et al. [12] suggested an ionoregulatory toxicity of CuNP to rainbow trout (Oncorhynchus mykiss). In addition, exposure to the $\mathrm{Cr}$ ion also inhibited the gill $\mathrm{Na}^{+} / \mathrm{K}^{+}$-ATP activity in Tilapia (Oreochromis niloticus) [35]. Given that the inhibition of the $\mathrm{Na}^{+} / \mathrm{K}^{+}$pump by metal ions is well known, the inhibition of CuNP on the 

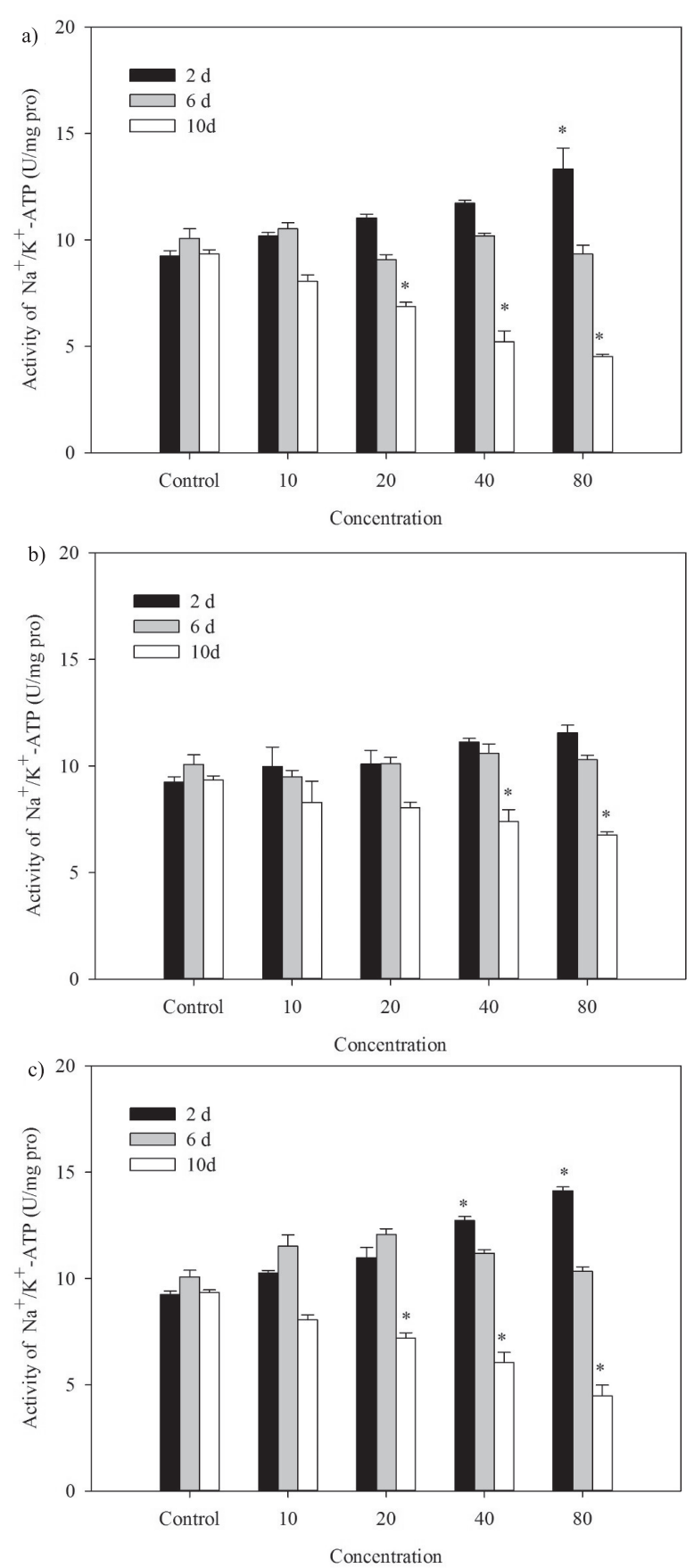

Fig. 3. The changes of gill $\mathrm{Na}^{+} / \mathrm{K}^{+}$-ATP activity in fish after exposure to a) CuNP, b) CrNP), and c) the mixtures. Asterisks indicate values that are significantly different from the control $(P<0.05)$.

$\mathrm{Na}^{+} / \mathrm{K}^{+}$-ATP activity in the gill of crucian carp may also be attributed to the release of metal free ions from the nanoparticles.

Currently, the determinant mechanism of nanoparticlemediated toxicity in organisms is related to the production of oxidative stress and reactive oxygen species (ROS), leading to a series of pathological events such as genotoxicity, inflammation, fibrosis, and carcinogenesis [36]. To protect organisms from oxidative damage, several antioxidant enzymes in organisms are activated
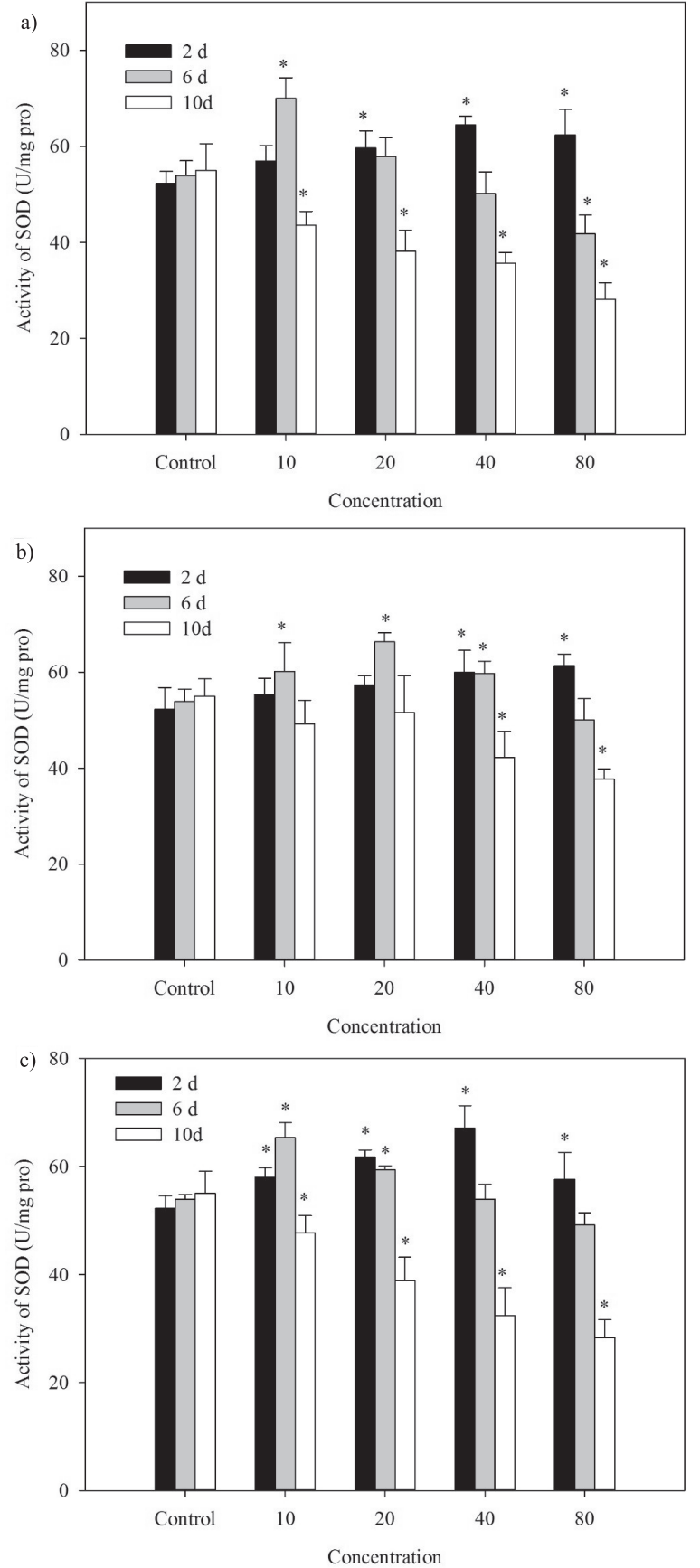

Fig. 4. The changes of liver SOD activity in fish after exposure to a) CuNP, b) CrNP, and c) the mixtures. Asterisks indicate values that are significantly different from the control $(P<0.05)$.

to scavenge oxidative stress, including the enzymes of SOD and CAT. As shown in Figs 4 and 5, both SOD and CAT activities in fish were significantly induced by the high concentrations of nanoparticles after exposure for $2 \mathrm{~d}$, indicating the excessive formation of superoxide anions and hydrogen peroxide in the liver, respectively. Fortunately, the elevated SOD and CAT enzymes may be sufficient to counteract the overproduction of ROS and convert them to harmless substances, such as water and oxygen, showing a defensive response. However, after exposure for $6 \mathrm{~d}$ to higher concentrations of $\mathrm{CuNP}$ and 

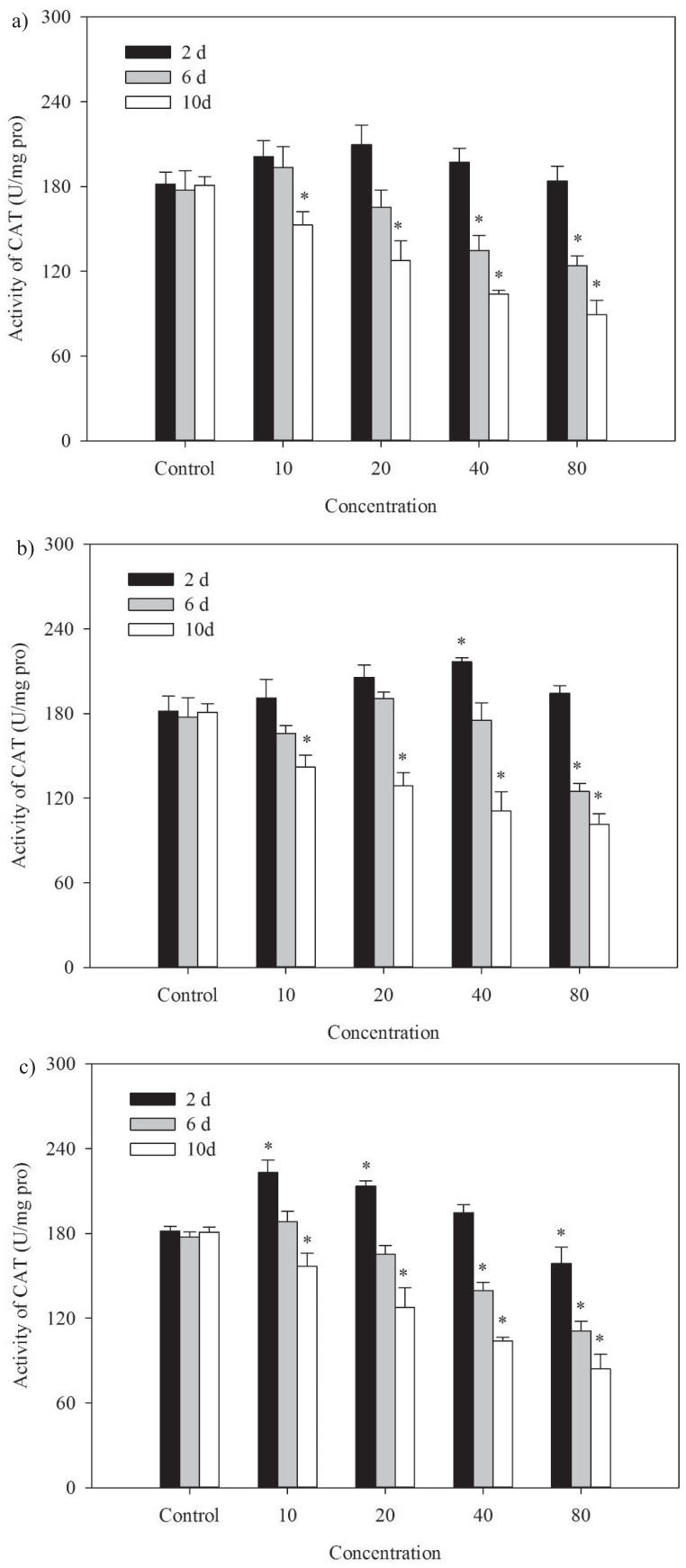

Fig. 5. The changes of o liver CAT activity in fish after exposure to a) CuNP, b) CrNP, and c) the mixtures. Asterisks indicate values that are significantly different from the control $(P<0.05)$.

CrNP (alone or in combination), the induced activities of antioxidant enzymes recovered to the baseline and even further decreased. In particular exposure for $10 \mathrm{~d}$, the SOD and CAT activities were inhibited by all treatments in a concentration-dependent manner, with the maximum inhibition rates of $49 \%$ and $51 \%$ by CuNP, $32 \%$ and $44 \%$ by CrNP, and $49 \%$ and $54 \%$ by the mixtures, respectively. The inhibitory effects in the antioxidant capacity of fish may result from the overproduction of ROS in the liver that may overwhelm the protective antioxidant effect caused by the enzymes. Meanwhile, the inactivation of antioxidant

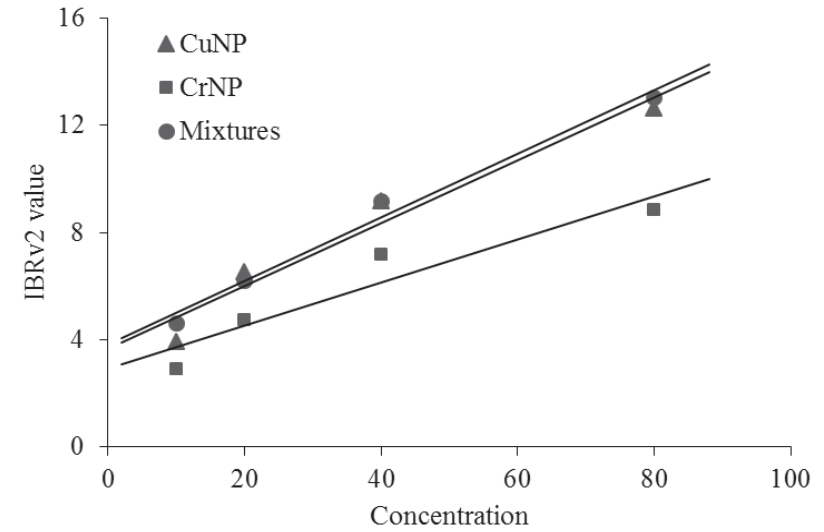

Fig. 6. IBRv2 values after exposure to different metallic nanoparticles for $10 \mathrm{~d}$.

enzymes may further result in the accumulation of ROS in cells, eliciting cell apoptosis through mitochondrial dysfunction [37]. Similarly, the activities of SOD and CAT in intestines of Epinephelus coioides were also obviously suppressed by CuNP in a concentration-dependent manner, causing a marked increase in lipid peroxidation and cell apoptosis in intestine [16]. Considering the ions of transition metals (e.g., $\mathrm{Cu}$ and $\mathrm{Cr}$ ) could result in the generation of ROS in organisms via the Haber Weiss and Fenton reactions [38], and the alterations of the antioxidant defense system induced by nanoparticles may be related to the dissolution of free metal ions from the surface of the nanoparticles. In addition, nanoparticles may also stimulate intracellular ROS generation via activation of NADPH-like enzyme system and immune cell after uptake through phagocytosis [36].

\section{Comparison of Potential Toxicity}

A common challenge in comparative toxicity using multi-biomarker responses is to provide an independent interpretation of each one. In order to simplify these interpretations, the IBRv2 index integrating each biomarker response was applied. This approach could provide both a graphical synthesis of each biomarker response and a numeric value that integrates all these responses at once. Meanwhile, the toxicity could also be distinguished among different compounds and different exposure concentrations according the IBRv2 values [39]. In the present study, the IBRv2 values in fish exposure for $10 \mathrm{~d}$ to different treatments are presented in Fig. 6 . Given that the IBRv2 needs reference values from nontreated organisms, the IBRv2 values in the control were always zero. In the same concentration, the mixtures showed similar values to the CuNP, and the low IBRv2 values were always observed in the CrNP treatment. As mentioned above, the IBRv2 index could provide a general description of health status of organisms, and the toxicity order of three metallic nanoparticles at the same concentrations could be tentatively proposed as: the mixtures $\approx \mathrm{CuNP}>\mathrm{CrNP}$, suggesting a synergistic toxicity 


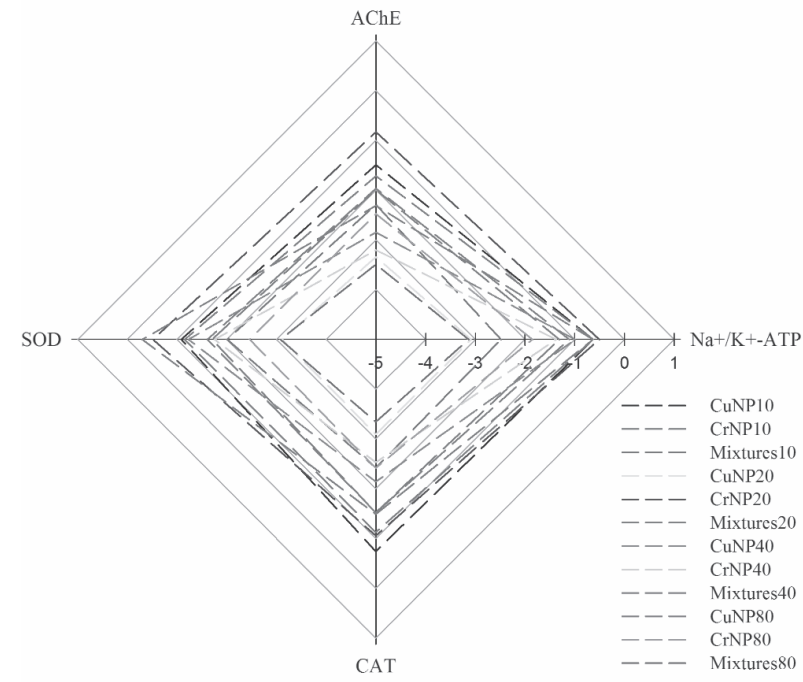

Fig. 7. A-value of each biomarker exposure to CuNP, CrNP, and the mixtures for $10 \mathrm{~d}$.

in the mixtures. This synergistic effect is in contrast with results reported by Tong et al. [8] that the inhibitory effect of $\mathrm{ZnO}$ nanoparticles on bacterial ATP levels was further reduced by the presence of $\mathrm{TiO}_{2}$ nanoparticles due to the adsorption of $\mathrm{Zn}$ ions. This inconsistency is likely due to the differences in organisms used in these two studies. As compared to bacterial cells, fish tested in the present study have many biofluids (e.g., gastric and intestinal fluids), which have the capacity to reduce the adsorption or/and enhance the desorption process of compounds on the nanoparticles [40]. In addition, the IBR values in all treatments increased in a concentrationdependent manner, with a correlation coefficient of 0.98 for CuNP, 0.90 for CrNP, and 0.95 for the mixtures. This concentration-dependent tendency was also found in Carassius auratus [41] and Limnodrilus hoffmeisteri [42] exposed to perfluorinated compounds and copper at various ranges of concentrations, which may be attributed to the high accumulations of test compounds in organisms. This suggests that the IBRv2 could be considered an efficient and easy tool for stakeholders to compare the toxicity of nanoparticles.

According to A-scores in the star plots, it is possible to identify which biomarker responses had the most important weight on the final IBR values. Moreover, the distinct scores of each biomarker response could also help to identify the differences in the modes of action of the nanoparticles. As shown in Fig. 7, it is clear that all biomarker responses were inhibited after exposure to metallic nanoparticles for $10 \mathrm{~d}$. The most important biomarker responses in toxicity were attributed to the enzymes involved in oxidative stress and neurological function in low concentration treatments, which implied that oxidative and neurological damage could be the major toxic mechanism for metallic nanoparticles at low concentrations. Devin et al. [43] also found that oxidative stress such as SOD and CAT induction seemed preponderant compared with the other biomarker responses in the IBR values, suggesting that oxidative damage was the toxicity pattern of metal-based nanoparticles in ragworm Hediste diversicolor and bivalve Scrobicularia plana. In addition, four biomarker responses were similarly sensitive at high concentrations, indicating a complex pathway of damage for fish by metallic nanoparticles.

\section{Conclusions}

In the present study, the results of acute toxicity demonstrated that both CuNP and CrNP were less toxic to crucian carp, while CuNP was more toxic than CrNP. In the sublethal toxicity test, the obviously inhibitory effects of metallic nanoparticles on various biomarker responses (AChE, $\mathrm{Na}^{+} / \mathrm{K}^{+}$-ATP, SOD, and $\mathrm{CAT})$ suggested an interference with the neurological function, osmoregulation, and antioxidant capacity of fish. These biomarker responses were further simplified and integrated to the IBRv2 index, which then provided a good discrimination of the potential toxicity of metallic nanoparticles toward fish. The mixtures exhibited comparable toxicity to $\mathrm{CuNP}$, while CrNP was the least toxic. These findings, therefore, indicate that metallic nanoparticles may pose risks to non-target organisms. Also, the application of IBRv2 may be a practical way for stakeholders to assess the toxicity of nanoparticles in the aquatic environment.

\section{Acknowledgements}

This study was supported by the National Natural Science Foundation of China (grant No. 51509071), the Natural Science Foundation of Jiangsu Province, China (grant No. BK20150801), the National Science Funds for Creative Research Groups of China (grant No. 51421006), the National College Students Innovation Experiment Program of Hohai University (201610294043), TAPP (PPZY2015A051), and the Priority Academic Program Development of Jiangsu Higher Education Institutions.

\section{References}

1. KLAINE S.J.,ALVAREZ P.J., BATLEY G.E., FERNANDES T.F., HANDY R.D., LYON D.Y., LEAD J.R. Nanomaterials in the environment: behavior, fate, bioavailability, and effects. Environmental Toxicology and Chemistry, 27 (9), 1825,2008

2. SCOWN T.M., VAN AERLE R., TYLER C.R. Review: do engineered nanoparticles pose a significant threat to the aquatic environment? Critical Reviews in Toxicology, 40 (7), 653, 2010.

3. HU X., LI D., GAO Y., MU L., ZHOU Q. Knowledge gaps between nanotoxicological research and nanomaterial safety. Environment International, 94, 8, 2016.

4. PAGET V., MOCHE H., KORTULEWSKI T., GRALL R., IRBAH L., NESSLANY F., CHEVILLARD, S. Human cell line-dependent WC-Co nanoparticle cytotoxicity and 
genotoxicity: a key role of ROS production. Toxicological Sciences, 143 (2), 385, 2015.

5. WATSON C., GE J., COHEN J., PYRGIOTAKIS G., ENGELWARD B.R., DEMOKRITOU P. High throughput screening platform for engineered nanoparticle-mediated genotoxicity using comet chip technology. ACS Nano, 8, 2118, 2014.

6. HUYNH K.A., MCCAFFERY J.M., CHEN K.L. Heteroaggregation reduces antimicrobial activity of silver nanoparticles: evidence for nanoparticle-cell proximity effects. Environmental Science \& Technology Letters, 1 (9), 361, 2014.

7. LI L., FERNÁNDEZ-CRUZ M.L., CONNOLLY M., CONDE E., FERNÁNDEZ M., SCHUSTER M., NAVAS J. $M$. The potentiation effect makes the difference: non-toxic concentrations of $\mathrm{ZnO}$ nanoparticles enhance $\mathrm{Cu}$ nanoparticle toxicity in vitro. Science of the Total Environment, 505, 253, 2015.

8. TONG T., WILKE C.M., WU J., BINH, C.T.T., KELLY J.J., GAILLARD J.F., GRAY K.A. Combined toxicity of nano- $\mathrm{ZnO}$ and nano- $\mathrm{TiO}_{2}$ : from single to multinanomaterial systems. Environmental Science \& Technology, 49 (13), 8113, 2015.

9. CHEN Z., MENG H., XING G., CHEN C., ZHAO Y., JIA G., CHAI, Z. Acute toxicological effects of copper nanoparticles in vivo. Toxicology Letters. 163 (2), 109, 2006.

10. MADHAVI V., REDDY A.V.B., REDDY K.G., MADHAVI G., PRASAD T.N.K.V. An overview on research trends in remediation of chromium. Research Journal of Recent Science. 2, 71, 2013.

11. WANG M.Q., XU Z.R. Effect of chromium nanoparticle on growth performance, carcass characteristics, pork quality and tissue chromium in finishing pigs. Asian Australasian Journal of Animal Sciences, 17 (8), 1118, 2004.

12. SHAW B.J., AL-BAIRUTY G., HANDY R.D. Effects of waterborne copper nanoparticles and copper sulphate on rainbow trout, (Oncorhynchus mykiss): physiology and accumulation. Aquatic Toxicology, 116, 90, 2012.

13. SONG L., VIJVER M.G., PEIJNENBURG W.J., GALLOWAY T.S., TYLER C.R. A comparative analysis on the in vivo toxicity of copper nanoparticles in three species of freshwater fish. Chemosphere, 139, 181, 2015.

14. SONG L., VIJVER M.G., PEIJNENBURG W.J. Comparative toxicity of copper nanoparticles across three Lemnaceae species. Science of the Total Environment, 518, 217, 2015.

15. XIAO Y., VIJVER M.G., CHEN G., PEIJNENBURG W.J. Toxicity and accumulation of $\mathrm{Cu}$ and $\mathrm{ZnO}$ nanoparticles in Daphnia magna. Environmental Science \& Technology, 49 (7), 4657, 2015.

16. WANG T., LONG X., CHENG Y., LIU Z., YAN S. The potential toxicity of copper nanoparticles and copper sulphate on juvenile Epinephelus coioides. Aquatic Toxicology, 152, 96, 2014.

17. LU G., YANG H., XIA J., ZONG Y., LIU J. Toxicity of $\mathrm{Cu}$ and Cr Nanoparticles to Daphnia magna. Water, Air, \& Soil Pollution, 228 (1), 18, 2017.

18. CAZENAVE J., BACCHETTA C., PARMA M.J., SCARABOTTI P.A., WUNDERLIN, D.A. Multiple biomarkers responses in Prochilodus lineatus allowed assessing changes in the water quality of Salado River basin (Santa Fe, Argentina). Environmental Pollution, 157 (11), 3025, 2009.

19. BELIAEFF B, BURGEOT T. Integrated biomarker response: a useful tool for ecological risk assessment. Environmental Toxicology and Chemical, 21, 1316, 2002.
20. SANCHEZ W., BURGEOT T., PORCHER J. M. A novel "Integrated Biomarker Response" calculation based on reference deviation concept. Environmental Science and Pollution Research, 20 (5), 2721, 2013.

21. DING J., LU G., LI Y. Interactive effects of selected pharmaceutical mixtures on bioaccumulation and biochemical status in crucian carp (Carassius auratus). Chemosphere, 148, 21, 2016.

22. SHAW B. J., HANDY, R. D. Physiological effects of nanoparticles on fish: a comparison of nanometals versus metal ions. Environment International, 37 (6), 1083, 2011.

23. HJ/T 154-2004. The guidelines for the hazard evaluation of new chemical substances, Ministry of Environmental Protection, PRC. 2004,

24. GRIFFITT R.J., WEIL R., HYNDMAN K.A., DENSLOW N.D., POWERS K., TAYLOR D., BARBER D.S. Exposure to copper nanoparticles causes gill injury and acute lethality in zebrafish (Danio rerio). Environmental Science \& Technology, 41 (23), 8178, 2007.

25. YANG L.H., FANG Z.Q., ZHENG W.B. Safety assessment and acute toxicity of heavy metals to crucian Carassius auratus. Journal of South China Normal University. 2, 101, 2003.

26. GRIFFITT R.J., LUO J., GAO J., BONZONGO J.C., BARBER D.S. Effects of particle composition and species on toxicity of metallic nanomaterials in aquatic organisms. Environmental Toxicology and Chemistry, 27 (9), 1972, 2008.

27. DE ASSIS C.R.D., LINHARES A.G., OLIVEIRA V.M., FRANÇA R.C.P., SANTOS J.F., MARCUSCHI M., CARVALHO JLB. Characterization of catalytic efficiency parameters of brain cholinesterases in tropical fish. Fish Physiology and Biochemistry, 40 (6), 1659, 2014.

28. ZHANG T., YANG M., PAN H., LI S., REN B., REN Z., SONG J. Does time difference of the acetylcholinesterase (AChE) inhibition in different tissues exist? A case study of zebra fish (Danio rerio) exposed to cadmium chloride and deltamethrin. Chemosphere, 168, 908, 2017.

29. XIA, J, ZHAO, H.Z., LU, G.H. Effects of selected metal oxide nanoparticles on multiple biomarkers in Carassius auratus. Biomedical and Environmental Sciences, 26 (9), 742, 2013.

30. DEARAÚJO M.C., ASSIS C.R.D., SILVAL.C., MACHADO D.C., SILVA K.C.C., LIMA A.V.A., DE OLIVEIRA M.B.M. Brain acetylcholinesterase of jaguar cichlid (Parachromis managuensis): From physicochemical and kinetic properties to its potential as biomarker of pesticides and metal ions. Aquatic Toxicology, 177, 182, 2016.

31. FONTE E., FERREIRA P., GUILHERMINO, L. Temperature rise and microplastics interact with the toxicity of the antibiotic cefalexin to juveniles of the common goby (Pomatoschistus microps): Post-exposure predatory behaviour, acetylcholinesterase activity and lipid peroxidation. Aquatic Toxicology, 180, 173, 2016.

32. CHAKRABORTI S., RAHAMAN, S.M. $\mathrm{Na}^{+} / \mathrm{K}^{+}$-ATPase: A Perspective. In Regulation of Membrane $\mathrm{Na}^{+}-\mathrm{K}^{+}$ATPase. Springer International Publishing. 15, 3, 2016.

33. MA Z., ZHENG P., GUO H., JIANG S., QIN J.G., ZHANG D., LIU X. Salinity regulates antioxidant enzyme and $\mathrm{Na}^{+} / \mathrm{K}^{+}$-ATPase activities of juvenile golden pompano Trachinotus ovatus (Linnaeus 1758). Aquaculture Research. 47, 1481, 2014.

34. WANG T., LONG X., LIU Z., CHENG Y., YAN S. Effect of copper nanoparticles and copper sulphate on oxidation stress, cell apoptosis and immune responses in the 
intestines of juvenile Epinephelus coioides. Fish \& Shellfish Immunology, 44 (2), 674, 2015.

35. BAYSOY E., ATLI G., CANLI M. The effects of salinity and salinity + metal (chromium and lead) exposure on ATPase activity in the gill and intestine of tilapia Oreochromis niloticus. Archives of environmental contamination and toxicology, 64 (2), 291, 2013.

36. MANKE A., WANG L., ROJANASAKUL Y. Mechanisms of nanoparticle-induced oxidative stress and toxicity. BioMed Research International. 942916, 2013.

37. MANNA P., GHOSH M., GHOSH J., DAS J., SIL P.C. Contribution of nano-copper particles to in vivo liver dysfunction and cellular damage: Role of $\mathrm{I} \kappa \mathrm{B} \alpha / \mathrm{NF}-\kappa \mathrm{B}$, MAPKs and mitochondrial signal. Nanotoxicology, 6 (1), 1, 2012.

38. KNAAPEN A.M., BORM P.J., ALBRECHT C., SCHINS R.P. Inhaled particles and lung cancer. Part A: Mechanisms. International Journal of Cancer, 109 (6), 799, 2004.

39. SANCHEZ-HERNANDEZ J.C., SANDOVAL M., PIERART A. Short-term response of soil enzyme activities in a chlorpyrifos-treated mesocosm: Use of enzyme-based indexes. Ecological Indicators, 73, 525, 2017.
40. WANG Z., ZHAO J., SONG L., MASHAYEKHI H., CHEFETZ B., XING B. Adsorption and desorption of phenanthrene on carbon nanotubes in simulated gastrointestinal fluids. Environmental Science \& Technology, 45 (14), 6018, 2011.

41. FENG M., HE Q., MENG L., ZHANG X., SUN P., WANG Z. Evaluation of single and joint toxicity of perfluorooctane sulfonate, perfluorooctanoic acid, and copper to Carassius auratus using oxidative stress biomarkers. Aquatic Toxicology, 161, 108, 2015.

42. MENG L., YANG S., FENG M., QU R., LI Y., LIU J., SUN C. Toxicity and bioaccumulation of copper in Limnodrilus hoffmeisteri under different $\mathrm{pH}$ values: Impacts of perfluorooctane sulfonate. Journal of Hazardous Materials, 305, 219, 2016.

43. DEVIN S., BUFFET P. E., CHÂTEL A., PERREINETTAJANI H., VALSAMI-JONES E., MOUNEYRAC C. The Integrated Biomarker Response: a suitable tool to evaluate toxicity of metal-based nanoparticles. Nanotoxicology. 11 (1), 1, 2017. 